\title{
Problems of learning in later Years: Using Agruso Lenses to Explore Adult Learning Experiences at two higher educational Institutions in Bulawayo, Zimbabwe
}

\author{
Whitehead Zikhali, PhD \\ Senior Lecturer: National University of Science and Technology, \\ Institute of Development Studies (NUST-IDS), Bulawayo, Zimbabwe.
}

\begin{abstract}
Learning is a lifetime experience and engagement. When pursued in formal circles, it is subject to personal (ability, cognition, commitment) and structural (income, class, gender) factors which determine how long a person pursues studies for. Using a modification of Agruso's gerontological lens, this paper discusses the experiences of students at Bulawayo Polytechnic College and the National University of Science and Technology. The paper stems from a qualitative, exploratory study of two academic groups at NUST Institute of Development Studies spanning over 36 months. It lays out the agenda for an understanding of continuing education not as a challenge which affects older generations but a complex which filters to middle and young adults in developing country contexts. The paper reveals that apart from challenges pertaining to acclimatising to new environments, technologies and processes, formal learning settings offer a raft of challenges for adult learners particularly relating to identity and cognitive aspects. From the challenges discussed, the researcher recommends that (i) continuing education be extended to more sections of society including the informal sector actors (ii) universities be more sensitive to socio-economic group differentials when offering courses for continued adult education.
\end{abstract}

KEYWORDS: adult learning, Agruso, elderly, culture, learning benefits.

\section{INTRODUCTION}

The first week of academic life for students in the advanced degree programmes offered at Zimbabwean universities offers a glimpse into the potential challenges and competencies of individuals enrolled. This is particularly the case for adult learners who join professional degree programmes and are constrained by various factors from exploring the entire gamut of services and amenities within the university. Acclimatizing to e-solutions, administrative procedures as well as navigating the campus prove to be compelling tasks. Although there may be a basis for exploring such experiences, this paper explores a much more complex dimension in looking at the actual learning experience itself. Using data collected at the Bulawayo Polytechnic College as well as National University of Science and Technology (NUST) over the course of two academic periods for higher national diploma, postgraduate diploma as well as master's students. The methodology section outlines specifics of how the study was designed, conducted and analyzed. For now, it is important to recognize that the Bulawayo Polytechnic College and NUST are two of Bulawayo's prime learning institutions and rate very highly in Zimbabwe as well. NUST in particular, is but one of many universities in Zimbabwe. It forms part of a rich and diverse tapestry of higher academic institutions offering degree programmes and professional academic courses. While the number and quality of degrees is not in dispute, it is however unclear what challenges adult learners within these universities face. Researchers (Mpofu, 2010; Mpofu, 2016; Kariwo, 2007) have drawn out issues which relate to some challenges including those at NUST, yet the analytical frames employed have almost exclusively been confined to identity theories and human development. The result is a lacuna 
in the literature employing frames from fields such as psychology in general and adult learning in particular. Employing the discursive frames propounded by Victor Agruso (1978), this paper asks what personal and institutional challenges adult learners enrolled at NUST face. In the process, it questions how different classes among the adults interpret and confront these challenges. The paper relies on a qualitative research design to unearth these issues. The structure of the paper follows four main sections after this introduction. A discussion of higher education and adult learning follows. It will be succeeded by the methodology section which outlines the research design, tools used, and analytical structure followed. Thereafter, a presentation and discussion of the findings is made. The conclusion and recommendations sections form the paper's epilogue.

\section{HIGHER EDUCATION IN ZIMBABWE}

Higher education in Zimbabwe has largely failed to keep up with demand. Prior to political independence, the system was largely racialized, accommodating white people while admitting relatively few blacks (Mungazi, 1989; Hungwe, 1994). The uneven access was compounded by the fact that few schools offered high school education for black students up to Advanced level -the university level entry qualification. As a result of the systematic segregation, black students were largely underrepresented at university-level study. Those who could not access local university education either acquired tertiary qualification outside the then Southern Rhodesia or via distance education through institutions such as the Central African Correspondence College (Hungwe K. , 1994). While such initiatives tilted the scales somewhat, the skewed distribution of resources and poorly trained staff (Parker, 1959) in African education continued to impinge against their advancement. The unequal representation is aptly captured by Mungazi whose findings are presented in Figure 1 below.

Figure 1: Student Enrolment by Race at the University of Rhodesia and Nyasaland 1957-1975

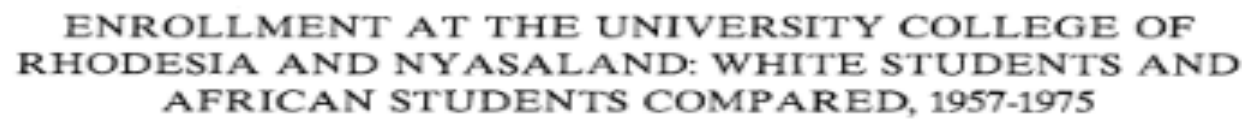

\begin{tabular}{|c|c|c|c|c|c|c|c|}
\hline Year & $\begin{array}{l}\text { African } \\
\text { Men }\end{array}$ & $\begin{array}{l}\text { Students } \\
\text { Women }\end{array}$ & Total & $\begin{array}{l}\text { White } \\
\text { Men }\end{array}$ & $\begin{array}{c}\text { Students } \\
\text { Women }\end{array}$ & Total & Grand Total \\
\hline 1957 & 7 & 1 & 8 & 33 & 27 & 60 & 68 \\
\hline 1960 & 44 & 5 & 49 & 91 & 68 & 159 & 208 \\
\hline 1965 & 165 & 9 & 174 & 345 & 153 & 498 & 672 \\
\hline 1970 & 339 & 24 & 363 & 378 & 196 & 574 & 937 \\
\hline 1975 & 477 & 84 & 561 & 549 & 251 & 900 & 1,361 \\
\hline
\end{tabular}

Source: Mungazi (1989, p. 280)

The table above reveals the uneven distribution of student enrolment by race and by gender. Evidently, white men tended to have the highest representation of the students enrolled followed by white women, black men and finally black women. The distribution mirrors the general ordering of society and economic resource distribution characteristic of preindependence as well as part of post-independence Zimbabwe.

After independence and with the massification of education (Shizha \& Kariwo, 2011), more blacks became eligible for higher education study. Through such utilitarian policies as 'Education for All', enrolment rates in primary education soared and similar gains were made in secondary education. However, in higher education demand outstripped stagnant supply. As Thonje (2016) notes, up until 1990, Zimbabwe had two universities. By the year 2000, these had increased to seven comprising of five state-owned universities and two private institutions. While the numbers have increased and continue to increase, demand continues to 
be high. Moreover, some researchers have argued that with declines in service delivery across many sectors, the quality of education provided in education has equally declined (Kariwo M. T., 2007). The debate on quality of higher education service delivery was and continues to be bolstered by general declines in economic and social indicators in Zimbabwe since the ESAP period. Conjoined with the declining standards at universities were declining incomes of the general populace, making it increasingly difficult to fund tuition for university students. The partial solution was to introduce a bonding system where the government would pay for a learner's tuition and the learner in turn became bound to work and reside in Zimbabwe for a specified duration upon completion of their studies. In spite of the state's efforts, students continued to be disgruntled. For their part, students at universities such as the University of Zimbabwe vented their frustrations at declining service delivery through student protests in the 1990s. Less violent strikes have been conducted in recent times as standards continue at low levels for both students, academic faculty and staff.

\section{ADULT LEARNING}

Adult formal learning in Zimbabwe has a long history in post-independence Zimbabwe where the government encouraged it to boost education access as well as indigenize the civil sector (Zvobgo, 1986; Shizha \& Kariwo, 2011). Besides being a derivative of government policy, many Zimbabweans of various economic capacity have sought advanced qualifications through various academic institutions. Universities are one such platform. However, universities are not detached from the society in which they operate. This therefore means that society and culture have a bearing on the university and vice versa. As Brink (2017) has noted, the society and culture in which we live is a source of understandings and of misunderstandings. Not only is Zimbabwe a potpourri of western, African, Islamic, Christian and traditional cultures but it is a carrier of multiple traditions, customs and expectations (Mapara, 2009). The result is a kaleidoscopic society with different points of emphasis on formal learning and higher education especially for adults. This type of learning is identified by various authors cited in Brink (2017) as conscientization, transformative learning, critical intelligence, useful knowledge' being critically reflective.

Employing Victor Agruso's taxonomy, adult learning spans over three distinct periods which are:

(a) Early adult hood

(b) Middle adulthood

(c) Late adulthood (Agruso, 1978)

Across these adult phases, continuing education, 'is the major intervention strategy designed in a variety of forms both to prevent obsolescence of one's skills and to enhance one's knowledge store, conditions which lead to successful adaptation throughout a lifetime' (Agruso, 1980, p.364). Human endeavor and effort towards continued improvement renders every stage of life open for learning, that is 'lifespan education'. Although largely concerned with gerontology, Victor Agruso notes that there are various learning stages through human life making the important observation that even in old age, formal learning is a boon. In support of this premise, and while also writing on the stages, Ted Fleming states that:

In our youth we work on who we are in the context of leaving home, going to college, exploring our sexuality, choosing our career (tentatively) and so on. In later and older adulthood, the context in which we must work on who we are is quite different. Family may be grown, grandchildren may have come along, job and career are ending, health becomes a greater concern, partners and friends are dying, a life has been lived and so on. The search for who we are goes on in this new context and these new agendas for our growth and development constantly emerge. Just as children and adolescents have 
developmental needs which are learning needs, so too do older adults. One difference is that there are not as many facilitators about who can, from their own experience, facilitate the transitional changes of later life. These are lifelong learning needs lifelong developmental needs! (Fleming, 1997)

Adulthood is often a period which lies concomitant with a search for identity. This makes it a period of immense self-discovery and transformation. In advanced countries, late adulthood is of major concern because of implications on social security, social welfare as well as economic activity (Boulton-Lewis, 2010). However, in Zimbabwe where the population dynamics point to a youthful population (Government of Zimbabwe, 2009). As such, the problem facing the country are unique, blending social welfare and security concerns with re-skilling in order to fit into the global, technology-driven economy. It is for this reason that the paper discusses learning across three age cohorts instead of sticking to gerontocratic lens.

Although adult learning is recognized as any learning or educational activity that occurs outside the structure of the formal education system that is undertaken by people who are considered to be adults in their society (Mpofu, Zimbabwe, 2016), the paper attends to those adults who are not necessarily above the age of 50 but adult learners who engage in bockrelease programmes. The demographic profile to these learners is outlined in the findings section of the paper. This is not to dispel the fact that older adults have fears too about returning to learn and there are well documented barriers: of being seen as too old, having poor health, lack of time, cost, out at night, transportation, absence of a companion, lack of information about what is available, fear of competition with younger adults, fear of exposure of their background, fear of the unknown and location (Fleming, 1997). Instead, assuming a broader demographic is a recognition of the intergenerational complexity of challenges which bring together young adults, middle adults as well as older adults or the aged. In addition, it is in cognizance of the fact that in contrast to advanced countries where lifelong learning is more of a personal choice, in Zimbabwe, it is a national and political objective (Kariwo M. , 2009).

\section{ADULT LEARNING IN ZIMBABWE}

According to Mpofu (2010), the architecture of adult learning in Zimbabwe follows five layers which are: governmental; parastatal; non-governmental; commercial, industrial and mining; and private institutional. To paraphrase his explanation, the layers are outlined as follows:

- governmental - government departments have educational components particularly in agriculture, education, health, labour, home affairs, and youth and employment creation. A second form entails departments that run adult learning organizations;

- parastatal - instrumental provision (for employees) to enhance service delivery; and, mainstream provision to the general public.;

- non-governmental - is divided into three tiers which are international nongovernmental organizations, local non-governmental organizations and cooperative societies;

- commercial, industrial and mining - which is largely meant for employees;

- private institutional - includes private colleges dominated by the 20-30-year-old age group (Mpofu, Zimbabwe, 2016).

Expanding on the what Mpofu (2010) identifies as 'private institutional' adult learning, Kariwo (2009) discusses the the role of university continuing education in Zimbabwe. At the time of his study, Kariwo noted that there were 'three institutions in Zimbabwe that had designated special units for continuing education, namely, the National University of Science and Technology (NUST), the Masvingo State University (MSU)i, and the Chinhoyi University of Technology (CUT)' (p.161). 


\section{METHODOLOGY}

Castles (2012:18) states that methods are 'specific techniques used to collect and analyze information or data' while 'methodology, by contrast, is about the underlying logic of research'. The methods are further categorized into those methods which are concerned with the collection of data; those statistical techniques which are used for establishing relationships between the data and the unknowns; and those methods which are used to evaluate the accuracy of the results obtained (ibid, 8). In contrast to research methods, research methodology 'involves the systematic procedures by which the researcher starts from the initial identification of the problem to its final conclusions' (Singh, 2006, p.79). The study was predominantly qualitative in nature although with a few descriptive detail quantitative elements. Research was conducted over the course of two academic periods for students enrolled in the higher national diploma, postgraduate diploma and master's degree programmes. These students were enrolled at the Bulawayo Polytechnic College (BPC) as well as within NUST's Institute of Development Studies (NUST IDS). NUST IDS is a specialist school situated within the Faculty of Commerce. The school offers postgraduate diplomas as well as master's degrees in the areas of Development Studies and Disaster Management. The standard and minimum academic period over which a student is enrolled is twelve (12) months for both higher national diploma and postgraduate diplomas, eighteen (18) months for master's students and thirty-six months for graduate degrees.

\section{RESEARCH INSTRUMENTS}

The research employed a mix of instruments to canvass as much data as possible. Interviews, self-administered questionnaires, in-class observations as well as focus group discussions were employed.

\section{Interviews}

The researcher conducted semi-structured interviews to collect data from students registered at BPC and NUST IDS. Semi-structured interviews entail a set of pre-arranged questions which follow a set structure. However, the researcher may follow-up on issues emerging from an interview and pose questions which may not be on the script but are related to the broad theme under scrutiny. The questions posed comprised of both close-ended and open-ended questions. Close-ended questions were used to capture basic student data while open-ended questions probed further in order to get a deeper understanding of issues such as decisionmaking processes and experiences. Interviews were conducted upon commencement of each course, midway through as well as immediately prior to completion.

\section{Questionnaires}

The researcher issued out self-administered questionnaires to cater for those students who for reasons such as time constraints and work commitments could not take part in interviews held over one sitting. To enable convenience, the questionnaire was availed both in physical form as well as online via Google forms. Electronic distribution allowed for easy access to the forms, convenient completion and prompt return. To ensure credibility of respondent feedback, emphasis will initially be placed around key events and critical moments in the learning processes and experiences of students in the school. The physical form of the questionnaire was of identical design to the online version. However, instead of students completing the form immediately upon receipt, they could take forms home, complete them and return within 48 hours of issuance.

\section{In-class observations}

Observations were chosen for several merits which they offer. These include (i) the researcher is enabled to record the natural behavior of the group. (ii) The researcher can even gather 
information which could not easily be obtained if he observes in a disinterested fashion. (iii) (Kothari, 2004, p.96). Through making observations in situ, the researcher was be able to verify the truth of statements made by participants in the context of a questionnaire or an interview. The researcher was able to observe how students interacted, engaged, navigated and related with their peers, with staff as well as with their course material during their study. As a lecturer within the department, it was very easy for the researcher to observe students during classes conducted either by the researcher himself or by other lecturers.

\begin{abstract}
ANALYSIS
Data collected was analyzed using various methods. Quantitative data on student numbers and enrolment figures and was collated in Statistical Package for Social Sciences (SPSS) for processing and analysis. Data fed into SPSS was first codified following themes identified. Codifying themes transformed some of the data into categorical form which was easier to analyze and present. Coding was necessary for efficient analysis and through it the several replies were reduced to a small number of classes which contained the critical information required for analysis (Kothari, 2004).
\end{abstract}

\title{
POPULATION AND SAMPLING
}

The population of the study comprised of all registered students at BPC and NUST. However, because of resource and logistical limitations, a sample of the population was employed to conduct the study. As a preliminary study into such experiences at BPC and NUST, the study did not concern itself much with possibility for generalizability. From this position as a starting point, the researcher employed a convenience sampling approach based on two criteria. The first was that a student was registered in a higher national diploma at BPC or advanced diploma/degree at NUST and the second was that they were above the age of eighteen. Justification for these two criteria lies in the fact that NUST IDS predominantly enrolls students who have gone through and completed undergraduate study while the higher national diploma is enrolled for by learners who have completed a diploma-level program at BPC. In most instances, the students are adults above the age of 22. Moreover, the students are enrolled on a block-release basis, which are essentially programs targeted at workers who want to upgrade themselves without taking extended leave of absence from work (Mpofu, Zimbabwe, 2016). The arrangement is such that learners come for lecture sessions at specific times of the semester, often spanning a fortnight and then disperse for assignments and preparation for examinations. These qualities mean that they face unique challenges and experiences compared to conventional students engaged with the university daily for three months at a time.

A convenience sample is defined by McBurney, $(1994$, p.203) as 'a nonrandom sample that is chosen for practical reasons'. In addition, convenience sampling is described as a procedure where 'population elements are selected for inclusion in the sample based on the ease of access' (Kothari, 2004, p.15). To this, Marczak, DeMatteo \& Festinger (2005, p. 83) add that a 'sample of convenience is simply a potential source of participants that is easily accessible to the researcher'.

The two student groups which participated in the study occupied a period of thirty-six months starting from May 2013. Since at the commencing period, no students had been enrolled in the graduate class, students who took part in the study were either in the higher national diploma $(n=10)$, postgraduate diploma $(n=47)$ or masters $(n=52)$ level of study. 


\section{THE SITE AND SETTING}

The National University of Science and Technology is a state-owned university which is founded under statutory law Chapter 25:13 as the National University of Science and Technology Act. According to Edward Shizha \& Michael Kariwo, the mission statement of NUST states:

The primary mission of the University is to serve the people of Zimbabwe. It strives to be a first-rate university nationally, regionally and in the general international fraternity of universities. NUST aims at the advancement of knowledge with a special bias towards the diffusion and extension of Science and Technology through teaching, pure research, applied research and fostering of close ties with industry (Shizha \& Kariwo, 2011, p.10).

The university was the second to be established in 1991, following the University of Zimbabwe. Situated in Bulawayo, it is easily accessible and avails services to residents of Bulawayo and people from outside of the area. NUST IDS is located 5.7 kilometers ${ }^{\mathrm{ii}}$ away from the main campus and lectures are offered across various sites which include among others, NUST main campus, Bulawayo Polytechnic main campus as well as rented sites in Harare.

Bulawayo Polytechnic College is also located in Bulawayo, offering a range of technical and commercial courses at diploma and higher national diploma levelii. The college has accommodation facilities which cater for a proportion of its student population. Those students who do not get accommodation must find residence off-campus within the city.

\section{FINDINGS AND DISCUSSION}

Before delving into the details of student experiences, it is prudent to lay out the demographic profile and characteristics of participants while also giving context in relation to the overall student complement at BPC and NUST IDS.

\section{Table 1: Descriptive data on participants}

\begin{tabular}{l|l} 
Characteristic & Description \\
\hline Average age & 32.7 years \\
Gender split & Male = 47.7\%; Female = 53.3\% \\
Total Postgraduate Diploma & 47 \\
Total Masters & 62 \\
Professional distribution & Civil Service $=17.4 \%$; Private Sector $=8.25 \% ;$ NGO \\
& sector $=47.7 \%$; Not formally employed $=26.6 \% ;$ \\
Physical (dis)ability & Yes $=5.5 \% ;$ No $=94.5 \%$
\end{tabular}

The students taking part in the study had an age range of between 25 and 67 years of age. Reasons for taking on continued learning ranged from the personal (challenge myself, lifetime ambition, family standards) to work-related (future job prospects, skills upgrade). In line with the three-tiered analysis employed by Agruso (1978), the participants were divided into three categories and specific themes discussed within each group. The distribution of participants within their three groups are laid out in Table 2 below.

Table 2: Participant distribution by level of adulthood

\begin{tabular}{|l|l|}
\hline Age Bracket & Number of participants \\
\hline Early Adulthood (22 to 29 years of age) & 37 \\
\hline Middle Adulthood (30 to 49 years of age) & 60 \\
\hline Late Adulthood (above 50 years of age) & 12 \\
\hline
\end{tabular}


Table 2 above reveals that most students enrolled into the postgraduate and masters level programs were in the middle adulthood bracket. This is hardly surprising given the fact that pursuing advanced academic qualifications is still a priority for many in this range in light of prospective work-related growth and employment prospects. These learners face or experience different problems in their different learning episodes. The study found that despite their thirst and quest for knowledge, lot of challenges affect the three groups of adults. These challenges are discussed in thematic form as political, economic, social, institutional and personal.

\section{POLITICS AND THE ECONOMY}

The general political and economic conditions plaguing Zimbabwe from 2013 appear to have played a significant role in the student's lives. For a start, the political cycle in 2013 disrupted plans made by many students to engage in various livelihood projects. Electoral cycles in Zimbabwe since the year 2000 have generally been characterized by uncertainty, trepidation and intermittent outbreaks of violence (Dorman, 2005; Tendi, 2013). This toxic air tends to stifle economic activity, and this played out in the first group of participants in 2013 when harmonized elections were held, marking and end to a government of national unity (GNU). In addition, economic prospects and outcomes appeared to take a gentle slide for many. This pattern persisted and gained momentum over time such that by the year 2015, some students indicated that they were enduring immense financial strain. Personal economic challenges affect the learners directly because they may mean failure to pay fees on time and therefore to attend lectures. In addition, they suggest difficulty in acquiring resources and learning paraphernalia. A key dimension in the complexity particularly among the middle adulthood and late adulthood groups is that economic challenges did not necessarily emerge from the harsh economic environment alone but from family commitments. An anecdote from one participant MaSibanda illuminates this position.

MaSibanda is a 46-year-old development officer in a local NGO. She started her Master of Science degree in Development Studies in May 2013. She is a single parent with three children all attending school. Between 2013 and 2014, her salary did not increase yet her tuition fees at NUST as well as tuition fees for two of her three children increased. This scenario meant that her real wages decreased in the time period. The demands placed on her meagre financial resources increased as her academic project progressed, and this strain affected her grades.

MaSibanda's experience is not representative of every adult student's experience. In the same vein, it is not exceptional as many others experienced the same. What is evident from findings is that economic pressures played an immense role in the experience of the student. Facing less commitments, study participants who were in young adulthood did not appear to face as much economic pressure as their other counterparts. One of the major reasons for this diminished pressure was that the many of participants (51\%) in this group did not have dependents. As a result, their income was much easier to manage. However, while the income was easier, the younger adults tended to have precarious forms of employment. Some were in the informal sector while others were employed on a temporary basis. This meant that although some of them did not have dependents, their unstable income streams were handled with as much caution as the stable incomes middle and late adulthood peers.

\section{SOCIAL}

The groups also identified social challenges which affect them. Among the Early adults it emerged that they go to learning institutions to acquire knowledge, look for partners and with the hope of futuristic gains (investment). The challenge which this posed was that advanced programs did not exactly flourish as platforms for social engagement with the hope of 
establishing amorous relationships. Instead, they were excellent platforms for business and career networking. There was also the complication of intergenerational relatedness. As already stated, the age range was 25 to 67 years. In some cases, young adults indicated that they were learning with people old enough to be their parents. Relating to one another as peers on a social level was therefore difficult although such boundaries were vastly diminished once in academic settings. Despite the diminished boundaries, cultural norms meant that young adults struggled to correct their older counterparts where debates emerged.

\section{INSTITUTIONAL}

The administrative arrangement of programs at both at BPC and NUST also posed some institutional challenges for learners particularly those who hailed from outside Bulawayo. This was complicated by administrative shortcomings in some instances which resulted in poor or inadequate information. Hence for students who resided in Harare but had to relocate to Bulawayo for their classes, a lot of logistical nightmares emerged. Many learners particularly in the middle and late adulthood cohorts had families and therefore relocating at short notice was quite problematic. Lizah, a student from Harare faced such challenges after she had initially been informed that she would be part of the Harare group. A few days prior to commencing her studies, she noticed that despite the earlier communication, her name was listed among the learners in the Bulawayo cohort. As a result, she had to make quick arrangements to move to Bulawayo for the duration of her classes and then return to Harare after. A related challenge in this regard was the provision of accommodation. NUST does not have enough accommodation facilities to cater for much of its student population. Given the fact that block release programs commence when conventional students are still engaged in their academic programs, this means that adult learners who make up the bulk of block release students do not have access to accommodation on campus. Their only recourse is temporary private accommodation where they do not or will not use a relative or acquaintance's residence.

\section{PERSONAL}

A small proportion (5.5\%) of the participants comprised of persons with disabilities. The challenge which was faced by these learners was mostly in terms of access to various facilities such as bathrooms on some campuses, lecture rooms, appropriate platforms for in-class presentations as well as access to distant campuses. These challenges were especially daunting for those in Middle and Late Adulthood. In Middle Adulthood, learners go to learning institutions to acquire knowledge, hoping futuristic gains (investment). However, they also face competing interests such as the desire for knowledge the quest for wealth/money. These pressures coalesce to complicate the lives of those who face institutional barriers such as the physically infirm because they face challenges navigating spaces as well as trying to attain their goals with little fuss.

Participants in Late Adulthood generally indicated that they sought to engage in continued learning mostly to gain current skills such as how they can invest their hard-earned cash, how to participate in new forms of livelihoods, what developmental trends and interventions they could co-opt into their knowledge base and so forth. While the curriculum offered at NUST attended to many of these aspirations and desires, the participants however encountered a litany of challenges. Their woes range from visual acuity, diminished physical strength, hearing impairment, difficulty in standing for long, a desire for periodic breaks in between lectures, 'enforced etiquette' and so forth. These challenges meant that in some cases, special provisions had to be made for in-class presentations. The researcher observed that presentations for group activities were almost exclusively assigned to young adults who were more adept at standing for long hours. While a younger person was assigned the task of presenting, older participants were often eager to respond to questions directed at their group representatives. 
Also, of note was the fact that breaks during lectures were often periods for micro-managing business, personal and family matters. The participants would often take the time to attend to various matters during the breaks, a pattern which was less prominent among the young adulthood cohort. An interesting dimension which emerged was what I have termed 'enforced etiquette' which essentially is the imposition of titles on the group. A simple example suffices.

Mr Mathunjwa joined the Master of Science in Disaster Management group in 2015, which was 24 months after the research had commenced. From the onset, he distinguished himself as different from the other students by emphasizing his role as a traditional leader. Not only was he a successful local businessman where he comes from, but he was the local chief. As such, he expected to be addressed by his official title despite being in an academic setting and therefore operating ex officio. The insistence to be called by his official title became a basis for derision from younger adults who did not recognize Mr Mathunjwa authority in an academic setting.

Although Mr Mathunjwa was an outlier due to his insistence, many other middle and late adults occupied respectable positions in organizations and in society. As a result, relations appeared to be layered to the disadvantage of younger adults. A questionable sense of academic peer hood existed.

\section{CONCLUSIONS AND RECOMMENDATIONS}

Formal continued learning is a common practice in Zimbabwe, having a history spanning from the period immediately after independence. While at college and university level the state has withdrawn its prominent role, individuals and organizations continue with it in the hope that their skills will be updated and enhanced. The anticipation is also that future economic prospects will be enhanced. Using perspectives from Agruso (1978), the paper has discussed the experiences of 109 students enrolled at the Bulawayo Polytechnic College and the National University of Science and Technology's Institute of Development Studies. The students have an average age of 32.7 years, ranging between 25 and 67 years of age. The study has revealed that students identified to varying degree, several challenges which affect them as they pursue their studies. The challenges have been thematically arranged into political, economic, social, institutional, and personal. Political and economic challenges affect all groups concerned albeit with different effect. Younger adults are not as challenged in economic terms since they have fewer dependents to support. This contrasts with middle and late adulthood groups who must contend with children and other dependents while also trying to get their studies completed. Personal challenges included such issues as disability concerns. The multi-sited campuses for example meant that students who already had many personal matters to contend with were thrust an added layer of complexity in moving from one campus to another, often with access challenges to contend with. Institutional matters related to administrative and logistical issues. Scarce accommodation and poor communication combined to create a mix of complications which learners particularly from outside of Bulawayo had to grapple with. Lastly, learner noted that there were social challenges within the learning setup. Relatedness between generations proved a challenge for some while a degree of enforced etiquette was also manifest. This translated in uneven social relations which to a much lesser degree played out in academic settings.

From the challenges discussed, the researcher makes the following set of recommendations:

(i) NUST and quite possibly other academic institutions in Zimbabwe take a more holistic approach to their programming in order to cater for adult groups whose needs are quite unique from those of conventional students. Such holistic approach could incorporate financial matters allowing for progressive payment of tuitions. In addition, communication channels could be improved in order to avoid complications such as 
students in one city moving to another for classes. In the same vein, accommodation could be pre-arranged so that students to not have to grapple with the added burden of seeking accommodation in new places at short notice.

(ii) The researcher also suggests that continuing education be extended to more sections of society including the informal sector actors where young adults are active. The enrolment shows that many of the participants were middle and late adults. Younger people who constitute the largest population demographic in Zimbabwe are excluded. Perhaps there is scope to reach out more to these people in order to ensure that a skills deficiency is not created especially in technology-centred and technical areas such as is offered at BPC.

(iii) Furthermore, it is recommended that universities be more sensitive to socioeconomic group differentials when offering courses for continued education. The fact that adult learners encounter intergenerational disconnect suggests that more could be done to ensure that learners relate as peer. This could be done through orientation programs which highlight the parity of all learners despite some having titles in society while others do not have privileges.

\section{References}

Agruso, V. M., 1978. Learning in the later years. 1st ed. New York: Academic Press.

Agruso, V. M., 1980. Guiding the Older Learner. Contemporary Educational Psychology, Volume 5, pp. 363-377.

Boulton-Lewis, G. M., 2010. Education and Learning for the Elderly: Why, How, What. Educational Gerontology, 36(3), pp. 213-228.

Brink, S., 2017. Learning in Later Years in the Lifelong Learning Trajectory. Journal of Intergenerational Relationships, 15(1), pp. 14-25.

Castles, S., 2012. Methodology and Methods: Conceptual Issues. In: African Migrations Research: Innovative Methods and Methodologies . Trenton: Africa World Press, pp. 15-36.

Dorman, S. R., 2005. Make Sure They Count Nicely This Time The Politics of Elections and Election Observing in Zimbabwe. Commonwealth \& Comparative Politics, 43(2), p. 155-177.

Fleming, T., 1997. Lifelong learning: the challenge of the latter years. [Online] Available at: http://www.leeds.ac.uk/educol/documents/000000319.html [Accessed 12 August 2017].

Government of Zimbabwe, 2009. Zero Draft - Medium Term Plan (MTP) January 2010 - December 2015. [Online] Available at:

http://www.zimtrade.co.zw/pdf/Governement\%2520policies/ZERO\%2520DRAFT\%2520MEDIUM\%2520TERM \%2520PLAN\%25202010-2015.pdf

[Accessed 12 June 2013].

Hungwe, K., 1994. Educational Policy in African Colonial Contexts: The Case of Instructional Media in Southern Rhodesia (1930-1980). African Study Monographs, pp. 1-36.

Kariwo, M., 2009. The Role of Continuing Education in Zimbabwe. In: A. A. a. K. D. Abdi, ed. Global Perspectives on Adult Education. New York: Palgrave Macmillan, pp. 159-173.

Kariwo, M. T., 2007. Widening Access in Higher Education in Zimbabwe. Higher Education Policy, p. 45-59.

Kothari, C. R., 2004. Research Methodology: Methods and Techniques. New Delhi: New Age International Publishers.

Mapara, J., 2009. Indigenous knowledge systems in Zimbabwe: juxtaposing postcolonial theory. The Journal of Pan African Studies, 3(1), pp. 139-155.

Marczyk, G., Dematteo, D. \& Festinger, D., 2005. Essentials of Research Design and Methodology. New Jersey: John Wiley and Sons.

McBurney, D. H., 1994. Research Methods. Pacific Grove: Brooks/Cole Publishing Company.

Mpofu, S., 2010. A survey of adult education provision in Zimbabwe, Cape Town: DVV international, Regional Office, Southern Africa.

Agruso, V. M., 1978. Learning in the later years. 1st ed. New York: Academic Press. 
Zikhali, W. (2019). Problems of learning in later Years: Using Agruso Lenses to Explore Adult Learning Experiences at two higher educational Institutions in Bulawayo, Zimbabwe. Advances in Social Sciences Research Journal, 6(4) 31-42.

Agruso, V. M., 1980. Guiding the Older Learner. Contemporary Educational Psychology, Volume 5, pp. 363-377. Boulton-Lewis, G. M., 2010. Education and Learning for the Elderly: Why, How, What. Educational Gerontology, 36(3), pp. 213-228.

Brink, S., 2017. Learning in Later Years in the Lifelong Learning Trajectory. Journal of Intergenerational Relationships, 15(1), pp. 14-25.

Castles, S., 2012. Methodology and Methods: Conceptual Issues. In: African Migrations Research: Innovative Methods and Methodologies . Trenton: Africa World Press, pp. 15-36.

Dorman, S. R., 2005. Make Sure They Count Nicely This Time The Politics of Elections and Election Observing in Zimbabwe. Commonwealth \& Comparative Politics, 43(2), p. 155-177.

Fleming, T., 1997. Lifelong learning: the challenge of the latter years. [Online] Available at: http://www.leeds.ac.uk/educol/documents/000000319.html [Accessed 12 August 2017].

Government of Zimbabwe, 2009. Zero Draft - Medium Term Plan (MTP) January 2010 - December 2015. [Online] Available at:

http://www.zimtrade.co.zw/pdf/Governement\%2520policies/ZER0\%2520DRAFT\%2520MEDIUM\%2520TERM \%2520PLAN\%25202010-2015.pdf

[Accessed 12 June 2013].

Hungwe, K., 1994. Educational Policy in African Colonial Contexts: The Case of Instructional Media in Southern Rhodesia (1930-1980). African Study Monographs, pp. 1-36.

Kariwo, M., 2009. The Role of Continuing Education in Zimbabwe. In: A. A. a. K. D. Abdi, ed. Global Perspectives on Adult Education. New York: Palgrave Macmillan, pp. 159-173.

Kariwo, M. T., 2007. Widening Access in Higher Education in Zimbabwe. Higher Education Policy, p. 45-59.

Kothari, C. R., 2004. Research Methodology: Methods and Techniques. New Delhi: New Age International Publishers.

Mapara, J., 2009. Indigenous knowledge systems in Zimbabwe: juxtaposing postcolonial theory. The Journal of Pan African Studies, 3(1), pp. 139-155.

Marczyk, G., Dematteo, D. \& Festinger, D., 2005. Essentials of Research Design and Methodology. New Jersey: John Wiley and Sons.

McBurney, D. H., 1994. Research Methods. Pacific Grove: Brooks/Cole Publishing Company.

Mpofu, S., 2010. A survey of adult education provision in Zimbabwe, Cape Town: DVV international, Regional Office, Southern Africa.

Mpofu, S., 2016. Zimbabwe. In: International Perspectives on Older Adult Education: Research, Policies and Practice. Geneva: Springer International Publishing, pp. 495-505.

Mungazi, D. A., 1989. A Strategy for Power: Commissions of Inquiry into Education and Government Control in Colonial Zimbabwe. The International Journal of African Historical Studies, pp. 267-285.

Parker, F., 1959. Education of Africans in Southern Rhodesia. Comparative Education Review, pp. 27-32.

Shizha, E. \& Kariwo, M. T., 2011. Education and Development in Zimbabwe: A Social, Political and Economic Analysis. Rotterdam: Sense Publishers.

Singh, Y. K., 2006. Fundamental of Research Methodology and Statistics. New Dehli: New Age International Publishers.

Tendi, B. M., 2013. Ideology, civilian authority and the Zimbabwean military. Journal of Southern African Studies, 39(4), pp. 829-843.

Zvobgo, R., 1986. Education and the Chalenge of Independence. In: I. Mandaza, ed. The Political Economy of Transition 1980-1986. Dakar: CODESRIA, pp. 319-354.

\footnotetext{
i Now Great Zimbabwe University

ii Google maps

${ }^{i i i}$ www.pindula.co.zw/Bulawayo_Polytechnic
} 